\title{
The Application of \\ Capillary Gas Chromatography to the Analyses of Acidic Constituents of Tobacco Leaf and Smoke*
}

\author{
by R. F. Arrendale, R.F. Severson and O.T. Chortyk \\ Tobacco Safety Research Unit, Agricultural Research Service, \\ United States Department of Agriculture, Athens, Georgia, U.S.A.
}

\section{SUMMARY}

Extensive details are presented for the laboratory preparation of specific glass capillary columns for the gas chromatographic analysis of various phenolic and acidic compounds of leaf and smoke. The chromatography of derivatized and underivatized mono- and dihydroxybenzenes, volatile acids, phenolic acids, and fatty acids is evaluated on both Pyrex glass and fused silica columns prepared by our methodology. The stability, efficiency, and low surface activity of columns prepared from different liquid stationary phases (SE-54, Superox-4, SP-1000, Silar 10C) are illustrated by numerous separations.

\section{ZUSAMMENFASSUNG}

Es wird ausführlich dargestellt, wie spezielle Glaskapillarrohre zur gaschromatographischen Bestimmung verschiedener phenolischer und saurer Blattabak- und Rauchbestandteile im Laboratorium hergestellt werden können. Das Trennvermögen von nach der beschriebenen Methode angefertigten Pyrex- und Quarzglassäulen wird durch die Chromatographie von derivatisierten und originären Mono- und Dihydroxybenzolen, von flüchtigen Säuren sowie Phenol- und Fettsäuren geprüft und bewertet. Unter Verwendung verschiedener stationärer flüssiger Phasen (SE-54, Su-

\footnotetext{
* Presented in part at the 184th National Meeting of the American Chemical Society, the Symposium on Chemistry of Tobacco and Tobacco Smoke, Kansas City, Missouri, 1982.

Received: 22od March 1983 - accepred: 13th Febroary 1984.
}

perox-4, SP-1000, Silar 10C) werden in Chromatogrammen an einer Reihe von Trennbeispielen Stabilität, Leistungsfähigkeit und Oberflächenaktivität der Säulen gezeigt.

\section{RESUMÉ}

L'article expose dans le détail la manière dont des tubes de verre capillaires spéciaux peuvent être fabriqués en laboratoire pour l'analyse en chromatographie gazeuse de différents composants phénoliques et acides de la fumée et de la feuille de tabac. Le pouvoir de séparation des tubes de pyrex et de quarz, confectionnés selon la méthode décrite, est étudié et jugé d'après la chromatographie de mono- et dihydroxybenzols dérivés et non-dérivés ainsi que d'acides volatiles, acides phénoliques et acides gras. En utilisant differentes phases liquides stationnaires (SE-54, Superox-4, SP-1000, Silar 10C), une série d'exemples de séparations chromatographiques sont présentés pour illustrer la stabilité, l'efficacité et l'activité de surface de ces colonnes.

\section{IN'TRODUCTION}

In recent years, we applied capillary gas chromatography (GC-2) to the separation, identification and quantitation of constituents of numerous complex mixtures contained in fractions of tobacco leaf, smoke, and pyrolyzates (1-13). In order to achieve the full power of this analytical technique, we also developed methodology for the rapid laboratory preparation of both Pyrex $^{\circ}$ and fused silica (FS) wall-coated open-tubular 
(WCOT) capillary columns with liquid stationary phases representing the entire range of polarities $(11,14-17)$. The ability to produce stable, efficient, low surface activity capillary columns allows greater flexibility in the application of GC-2. Columns can be quickly and easily produced and are tailor-made for specific samples or classes of compunds. A chromatographer may approach the application of GC-2 with less regard for the fate of the column because a replacement column can be rapidly obtained. On the other hand, a chromatographer using a purchased capillary column may become reluctant to try new ideas for fear of damaging an expensive purchased column. This tends to suppress innovative application of this powerful technique. Also, the ability to prepare columns insures availability of a wider variety of liquid phases and a wider range of liquid phase film thickness. These considerations will be covered later in detail.

Tobacco leaf and smoke contain a variety of acidic constituents, some of which possess important health implications, while others contribute to the flavor and aroma of tobacco smoke (18-25). Mono- and dihydroxybenzenes, contained in a weakly acidic fraction of cigarette smoke, are tumor promoters, especially dihydroxybenzenes like catechol and its derivatives (1824). Phenols also contribute significantly to the aroma of smoke (25). Polyphenols, which are considered to be important precursors of the smoke phenols, can be readily analyzed by high pressure liquid chromatography (26): The volatile fatty acids $\left(\mathrm{C}_{2}-\mathrm{C}_{10}\right)$ are responsible for the characteristic flavor and aroma of Oriental tobaccos. Acidic constituents in smoke and leaf represent a wide variety of structures and volatilities, ranging from the volatile acids and phenols to the large, relatively non-volatile long-chain fatty acids and polyphenols. Efficient, rapid, and reproducible GC-2 analyses require careful consideration of liquid stationary phase, film thickness, column length and diameter, and proper injection techniques. Thus, the separation and quantitation of acidic constituents of tobacco and tobacco smoke present the chromatographer with challenging problems.

\section{EXPERIMENTAL*}

\section{Preparation of Wall-Coated Open-Tubular (WCOT) Capillary Columns}

Before the introduction of fused silica (FS) capillary tubing, most columns were made from Pyrex (borosilicate) or soda lime glasses. During this time, commercial columns were lacking on variety of stationary phases and film thicknesses and were of generally lower quality than those available today. Under the circumstances, we were compelled to produce our own columns and now reap the benefits of this decision. Our methodology for the preparation of capillary columns with Pyrex glass $(14,15)$ was readily adaptable to the preparation of 'FS columns, which are now exclusively employed in our capillary GC work $(11,16,17)$.

Methods for the laboratory preparation of columns should adhere to the following criteria: 1. the techniques must be simple so that technical personnel can quickly master them, 2. the methods must be rapid so that time and materials can be efficiently utilized, 3. the procedure must consistently produce columns of good and sometimes excellent quality. Our methodology fulfills all of these criteria $(11,14-17)$.

The many advantages of columns constructed of FS tubing over traditional Pyrex or soda lime glass columns are well documented in the published literature (27-31). Our general scheme for the preparation of FS capillary columns is shown in Figure 1. Practical details of our column preparation and evaluation procedures may be found elsewhere $(11,16,17)$. Other techniques for capillary column preparation may also be found in the published literature $(27,31)$.

\footnotetext{
* Reference to a company or product name does not imply approval or recommendation by the United States Department of Agriculture.
}

Figure 1.

Preparation of fused silica (FS) glass wall-coated open-tubular (WCOT) caplliary columns using the Superox-4 pretreatment and deactivation procedure.

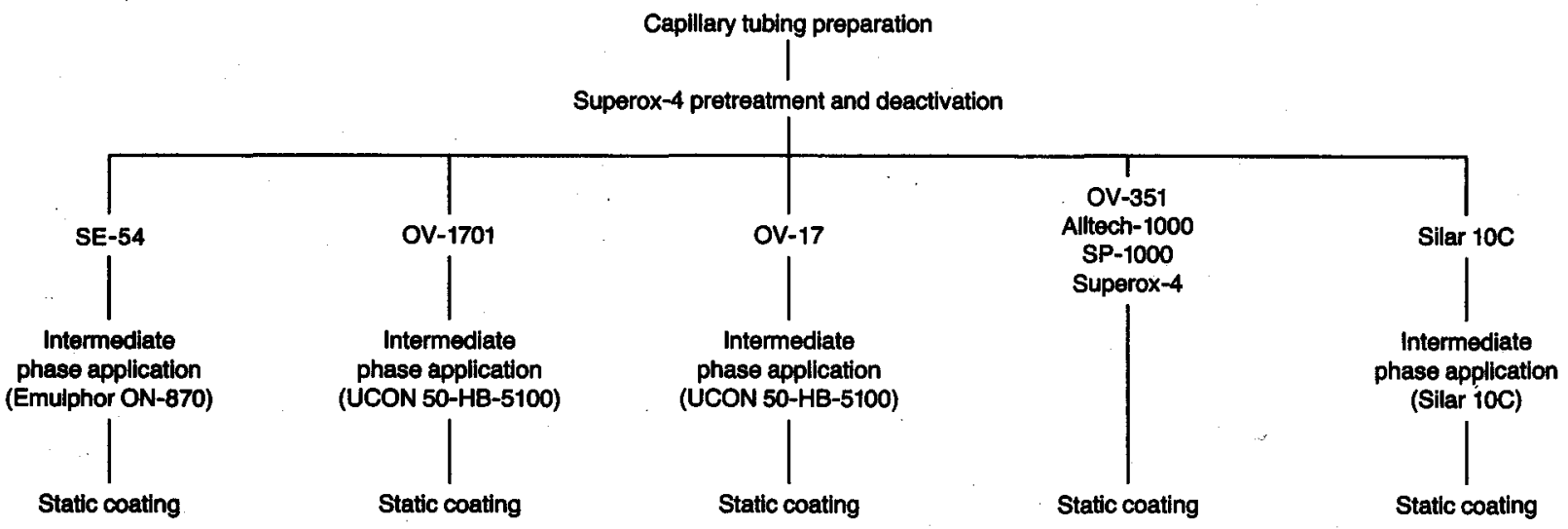


Table 1. Statlonary phases.

\begin{tabular}{|c|c|c|c|c|c|c|}
\hline \multirow{2}{*}{ Liquid phase } & \multirow{2}{*}{ Description } & \multicolumn{5}{|c|}{ McReynoids' constants * } \\
\hline & & benzene & butanol & 2-pentanone & nitropropane & pyridine \\
\hline SE-54 & $5 \%$ phenyl, $1 \%$ vinyl, methyl silicone & 033 & 072 & 066 & 099 & 067 \\
\hline OV $-1701^{* *}$ & $\begin{array}{l}7 \% \text { phenyl, } 7 \% \text { cyanopropyl, methyl } \\
\text { silicone }\end{array}$ & 067 & 170 & 153 & 228 & 171 \\
\hline OV-17 & $50 \%$ phenyl, methyl silicone & 119 & 158 & 162 & 243 & 202 \\
\hline Superox-4 & $\begin{array}{l}\text { polyethylene glycol }\left(4 \times 10^{6} \text { molecular }\right. \\
\text { weight })\end{array}$ & 296 & 568 & 349 & 555 & 470 \\
\hline $\begin{array}{l}\text { Carbowax } \\
20 \mathrm{M}\end{array}$ & $\begin{array}{l}\text { polyethylene glycol }\left(2 \times 10^{4} \text { molecular }\right. \\
\text { weight })\end{array}$ & 322 & 536 & 368 & 572 & 510 \\
\hline$O V-351^{+}$ & & 335 & 552 & 382 & 583 & 540 \\
\hline$S P-1000^{+}$ & $\begin{array}{l}\text { terephthalic acid, derivative of Carbo- } \\
\text { wax } 20 \mathrm{M}\end{array}$ & 322 & 555 & 393 & 583 & 546 \\
\hline Silar $10 C$ & $100 \%$ 3-cyanopropyl silicone & 520 & 757 & 660 & 942 & 800 \\
\hline
\end{tabular}

\section{Stationary Phase Selection}

In general, the polarity of the stationary phase should match that of the sample components; therefore, the number of phases need only be a few, providing they span the entire polarity range. Table 1 contains descriptions and McReynolds' constants for the stationary phases used in our laboratory.

Tobacco and tobacco smoke contain many components with varying degrees of acidity. Many mildly acidic components, occurring in steam volatile extracts of tobacco and smoke, can be analyzed underivatized on any of the acidic polar liquid phases, such as SP-1000, OV-351 or AT-1000. Flavor chemists often characterize components in volatile flavor extracts on both polar and non-polar phase columns such as SP-1000 or SE-54. Other phases, such as the medium polarity OV-1701 and OV-17, may also be useful for GC analyses of volatile flavor and aroma compounds. Volatile fatty acids, with chain lengths from $1-10$ carbon atoms, may be separated underivatized on SP-1000 columns (16). Long-chain fatty acids are most effectively analyzed as their methyl esters, using very polar cyanopropylsilicone liquid phases, like Silar 10C (11). For this reason, we developed the method for preparing FS Silar 10C WCOT capillary columns, which are especially useful for the separation of cis-trans isomers of unsaturated fatty acids, as methyl esters (11). We have found that Superox-4 columns can also be used to separate fatty acid methyl esters (FAME), although their selectivity is lower than that of Silar $10 \mathrm{C}$ columns $(15,16)$. Some acidic components are difficult to chro- matograph as underivatized compounds, because of the complex nature of the samples and labile character of the components. Phenolics from cigarette smoke are a good example and are most easily analyzed as their trimethylsilyl (TMS) derivatives (4) on non-polar phase columns such as those coated with SE-54. Derivatization (TMS) of acidic constituents provides the following improvements in capillary gas chromatography: 1 . increased component volatility, 2 . decreased component polarity, 3. separation on higher efficiency nonpolar phase columns, based on the aromatic or aliphatic portion of the molecule, and 4 . increased response to a flame ionization detector (FID).

\section{Stationary Phase Film Thickness}

One often neglected aspect of GC-2 is the film thickness of the stationary liquid phase. The magnitude of the film thickness has drastic effects on many characteristics of the column. It has been shown that doubling the film thickness can increase the elution temperature of components by as much as $20^{\circ} \mathrm{C}$ (32). Thin film capillary columns have the highest efficiencies and the shortest analysis times. Increasing the film thickness increases the capacity, decreases the surface activity, and increases column lifetime. Thus, the film thickness should be optimized for the particular application of the column. Thin film columns should be used for high molecular weight materials which are relatively nonvolatile, while thick film columns are useful for low molecular weight, highly volatile components. Routine 
analyses can be made more efficient by simply reducing the film thickness, which in turn reduces analysis time. Non-polar gum phases, like SE-54, have the greatest range of film thicknesses. We have utilized SE-54 columns for analyses of tobacco leaf and smoke components, ranging from highly volatile, low molecular weight to high molecular weight, low volatility materials $(1,4,6-8,10,12)$.

\section{Column Length and Inside Diameter}

The efficiency of a capillary column (per unit length) depends mainly on three factors, other than carrier gas velocity: 1. the stationary phase film thickness (the thinner the film the higher the efficiency), 2. the uniformity of the stationary phase film, and 3. the inside diameter of the capillary column (the smaller the diameter the higher the efficiency). Most columns used in the early days of GC-2 were in excess of $50 \mathrm{~m}$ in length and of small bore $(0.2-0.25 \mathrm{~mm}$ inside diameter). This restriction arose from an early fixation for achieving maximum efficiency from capillary columns. The pressure drop across long, narrow bore capillary columns is quite large and requires relatively high carrier gas head pressures. This places a strain on seals, making leaks more probable. The flow through a long narrow bore $(0.2-0.25 \mathrm{~mm})$ column is low, even with high head pressures, making transfer of sample components to the column more difficult with traditional split-splitless inlet systems. Narrow bore capillary columns, even those with thick liquid phase films, contain very little liquid phase and, therefore, have a low sample capacity and a narrow dynamic range of component concentration. If a desired separation cannot be achieved with a 25$30 \mathrm{~m}$ column, we have found that a $50 \mathrm{~m}$ column will probably not improve it greatly.

Shorter $(10-30 \mathrm{~m})$, wider bore $(0.3 \mathrm{~mm}$ inside diameter) capillary columns possess most of the advantages and few of the disadvantages of long, narrow bore columns. Shorter columns have almost the same usable efficiency as the longer columns, but with a lower pressure drop across their length. Wider bore columns also have a lower pressure drop and a higher sample capacity than narrow bore columns. We have seen this evolution in column dimensions in our own laboratory. Our average column now is $25 \mathrm{~m} \times 0.3 \mathrm{~mm}$ inside diameter. Two other factors have increased our use of $0.3 \mathrm{~mm}$ inside diameter glass capillary columns: 1 . sample capacity requirements for capillary $\mathrm{GC} / \mathrm{MS}$ analyses and 2. the development and refinement of cold on-column capillary injection techniques (33-35).

\section{Capillary Inlet Design and Injection Techniques}

As with the capillary columns themselves, early commercial capillary inlet systems were of poor quality, as measured by today's standards. Because of unaccept-
Flgure 2.

Converted, all-glass caplllary Inlet system, based on standard packed column injection port.

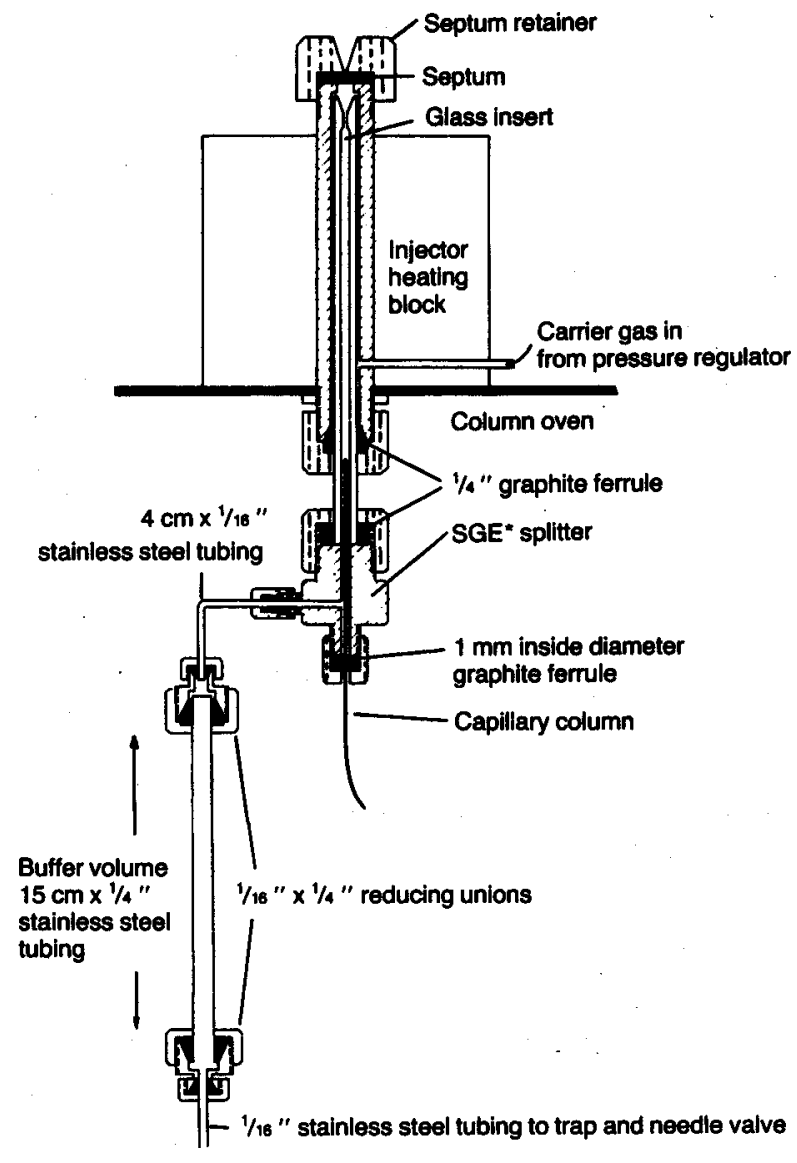

* Scientific Glass Engineering.Pty., Ltd., Melbourne, Australla.

able results obtained with commercial inlet systems, we were forced to develop our own inlet design. A diagram of the capillary inlet system used for the vast majority of our work (36) is shown in Figure 2. This capillary inlet system was developed in our laboratory using the normal Hewlett-Packard 5700-5800 packed column injection port; a glass insert, made from standard Pyrex glass tubing ( $1 / 4 \mathrm{in}$. outside diameter, $2 \mathrm{~mm}$ inside diameter); an SGE* $1 / 4$ in. $\times 1 / 16$ in. tee joint; $1 / 4$ in. $X$ $1 / 16$ in. stainless steel tubing; and a needle valve for control of the split vent. For splitless injection, the buffer volume should be replaced with $1 / 16$ in. stainless steel tubing. This capillary inlet system was designed for easy disassembly by the use of graphite ferrules for all connections. The glass inserts are made in a glass shop and are very inexpensive when compared with glass inserts purchased for commercial capillary column inlet systems. In almost all instances, glass inserts for commercial inlets can be manufactured in a glass-blowing shop at substantial cost reduction over commercial prices. Advances in theory and design of inlets and the advent of fused silica capillary tubing have made the use of capillary columns the mainstay of gas chroma-

* Scientific Glass Engineering Pty., Ltd., Melbourne, Australia. 
Figure 3.

Gas chromatogram of a gel chromatography fraction (GF-40) of tobacco smoke [mono- and dihydroxybenzenes as their trimethylallyl (TMS) derlvatives]. Conditions: wall-coated open-tubular (WCOT) capillary column (Pyrex glass SE-54); $40-200^{\circ} \mathrm{C}$ at $2^{\circ} / \mathrm{min} ; 32 \mathrm{~cm} / \mathrm{s}$ He flow; split injection mode; FID; $30 \mathrm{~m} \times 0.25 \mathrm{~mm}$ inside diameter.

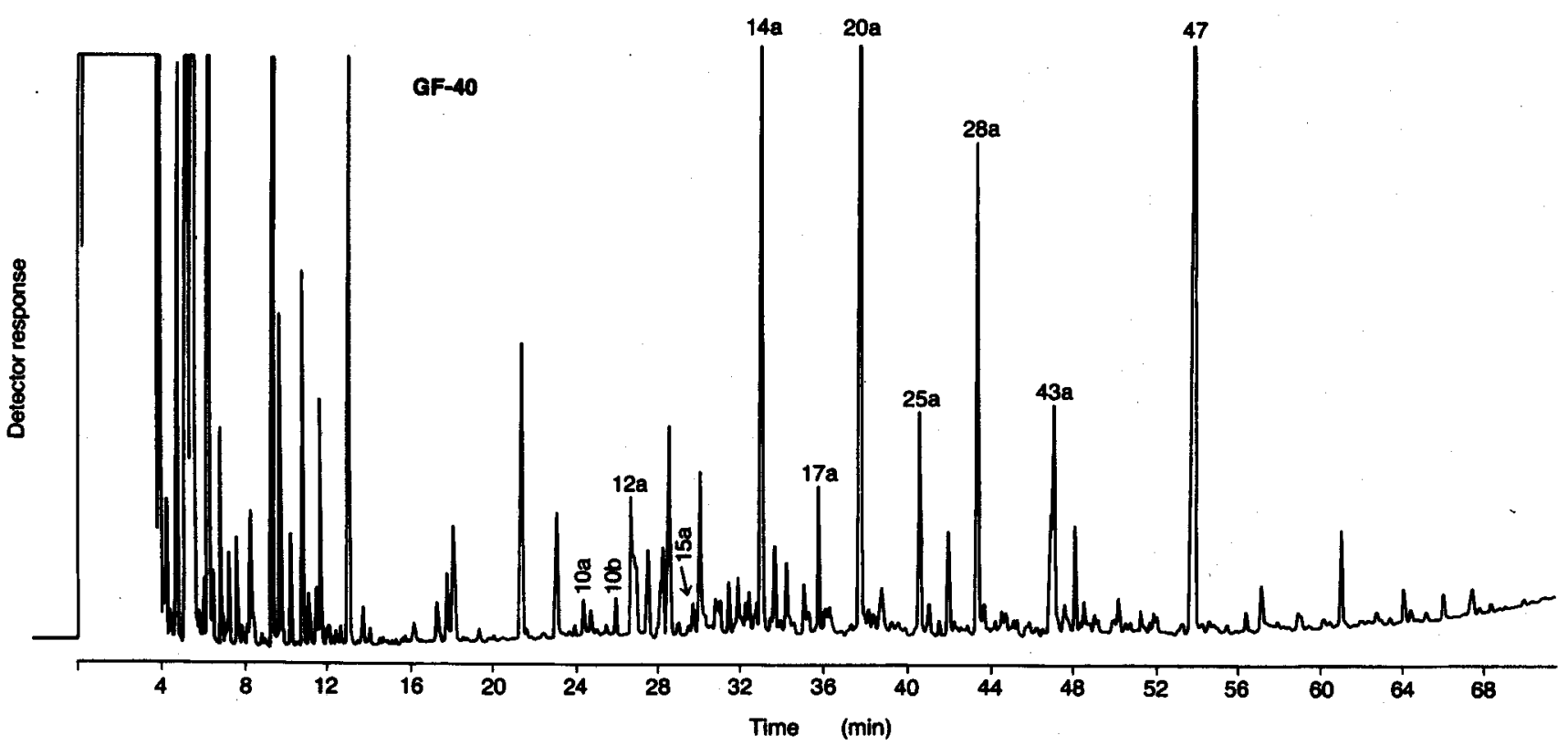

10a: $m$-isopropylphenol

10b: $p$-isopropylphenol

12a: 0-sec-butylphenol and $m$-n-propylphenol

14a: $m$ - and $p$-tert-butylphenol

15a: p-sec-butylphenol 17a: $p$-vinylguaiacol and trimethylguaiacol

20a: eugenol

25a: cis-isoeugenol

28a: trans-isoeugeno

43a: 2,3-dimethyl-1,4-naphthoquinone and 2,3,6-trimethyl-1,4-naphthoquinone tography. Several good quality inlet systems for GC-2 are now commercially available. However, most first hand information concerning equipment of this nature is presented by sales representatives who are often uninformed or unqualified to rationally discuss inlet theory, design and application. Thus, as in all cases, the consumer should beware. Recent studies have further explained and refined the splitless and cold on-column injection techniques $(34,35)$. We have recently modified our inlet system (Figure 2) to allow cold on-column injection and details will soon be available (33).

\section{RESULTS AND DISCUSSION}

The non-polar stationary phase, SE-54, was found to be the most useful liquid phase for analyses of tobacco and smoke components $(1,4,6,7,9,10,12)$. The trimethylsilyl derivatives (TMS) of the mono- and dihydroxybenzenes from tobacco smoke and the phenolic acids of leaf and smoke can be readily analyzed on fused silica SE-54 wall-coated open-tubular columns (4). There are many advantages to analyzing phenolics (as TMS) on these non-polar columns. These compounds occur in the very complex matrix of cigarette smoke and attempts to isolate and purify these labile components often result in serious losses, especially of the important dihydroxybenzenes, catechol and hydroquinone. Thus, direct analysis of these compounds from whole cigarette smoke condensate (CSC) was a logical approach, but GC-2 analysis of underivatized CSC was very difficult. The dihydroxybenzenes separated poorly or not at all. The capillary inlet glass liner became rapidly contaminated with other non-volatile smoke components and required replacement after virtually every injection.

On the other hand, analyses of total CSC constituents as their TMS derivatives was a relatively simple procedure. The CSC phenolics were derivatized by treatment with a silylating reagent to form the non-polar TMS ethers, which were then separated on SE-54 columns like paraffinic hydrocarbons (4). The elution order of components was more predictable and the TMS phenolics were stable and less likely to adsorb onto dirty injection port liners. The addition of the TMS groups also increased the flame ionization detector (FID) response to phenolics by decreasing their carbon/hydrogen ratio, which in effect lowers the detection limit. Peaks were sharp and separation efficiencies were higher, as non-polar phase capillary columns are inherently more efficient than polar columns.

Snook et al. have made extensive use of gel permeation chromatography to isolate and identify phenols and phenolic acids from tobacco smoke $(37,38)$. GC pro- 
Figure 4.

GC-2 chromatogram of a trimethylsilyl-derlvatized phenolic acid fraction from tobacco smoke

on a fused sillca SE-54 wall-coated open-tubular (WCOT) caplliary column.

Conditions: $60-280^{\circ} \mathrm{C}$ at $4 \% \mathrm{~min} ; 30 \mathrm{~cm} / \mathrm{s}$ He flow; split injection mode; FID; $20 \mathrm{~m} \times 0.3 \mathrm{~mm}$ inside diameter.

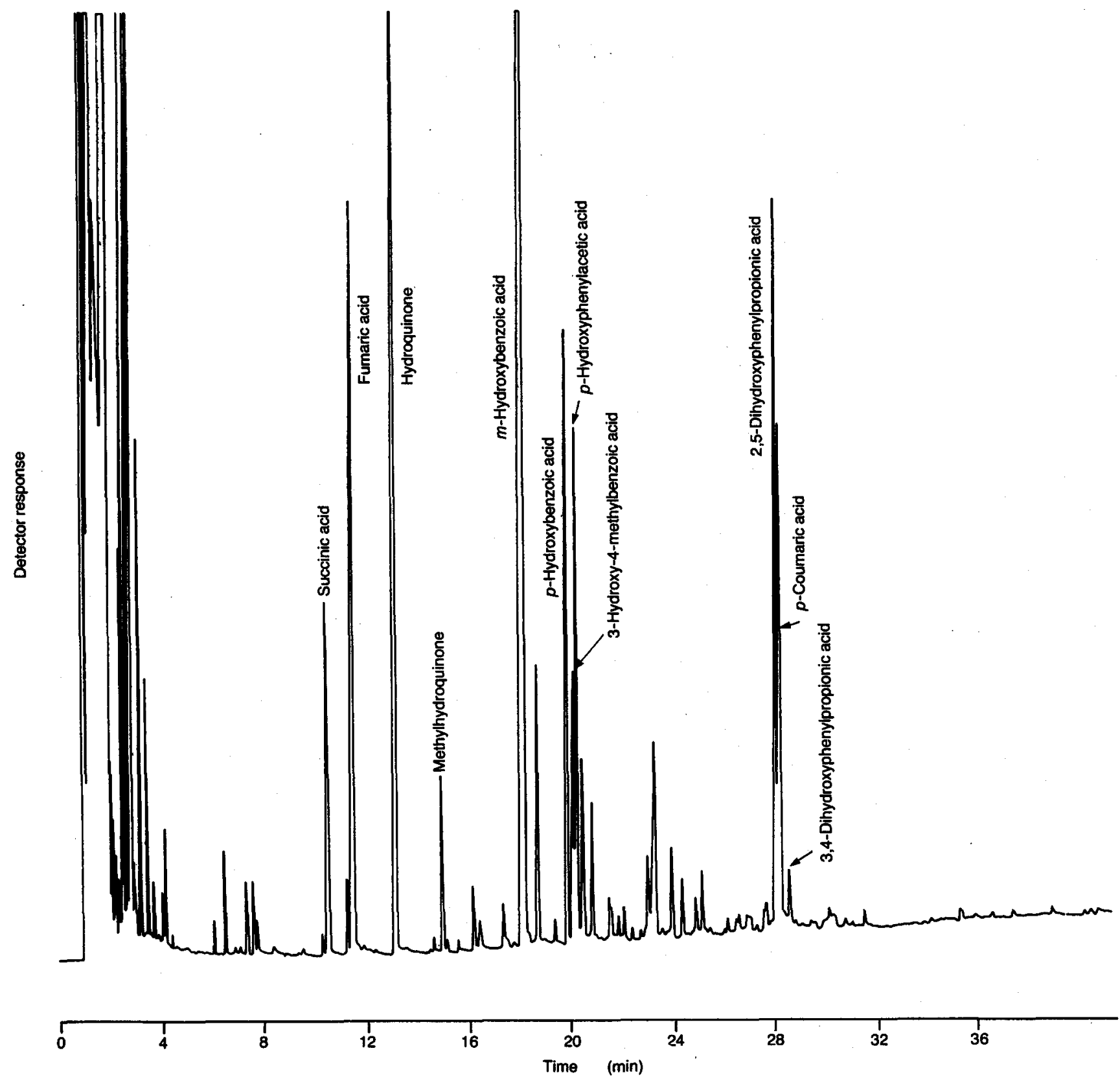

files of a gel fraction of mono- and dihydroxybenzenes (TMS) (Figure 3) and of phenolic acids (TMS) (Figure 4) were obtained on fused silica SE-54 capillary columns. Due to high polarity, low volatility and severe decomposition, phenolic acids are very difficult to analyze by GC without derivatization. However, their TMS ethers chromatograph well on SE-54 columns. The procedure for TMS derivatization of mono- and dihydroxybenzenes and phenolic acids is given elsewhere (4).

Steam volatile fractions of tobacco and smoke contain acidic components as well as bases and neutrals. These fractions can be separated on SP-1000 capillary columns or columns with equivalent phases, such as OV-351 or AT-1000. A chromatogram of the steam distillate fraction of NC-95 tobacco is shown in Figure 5. Volatile fatty acids $\left(C_{2}-C_{10}\right)$ are known to be responsible for the characteristic flavor and aroma of Turkish tobacco $(12,39-41)$. The acidic SP-1000 capillary column can be used for the separation of these volatile fatty acids (16). These volatile acids are also part of the sucrose esters that have been recently found on the surface of green leaves of Turkish-type tobaccos (12). A pure fraction of sucrose esters was also ob- 
Figure 5.

Chromatogram of a steam distilled fraction of NC-95 tobacco on a fused sillica SP-1000 wallcoated open-tubular (WCOT) capillary column. Conditions: $45-2500^{\circ} \mathrm{C}$ at $4^{\circ} / \mathrm{min} ; 30 \mathrm{~cm} / \mathrm{s} \mathrm{H}_{2}$ flow; splitless injection mode; FID; $40 \mathrm{~m} \times 0.2 \mathrm{~mm}$ inside diameter.

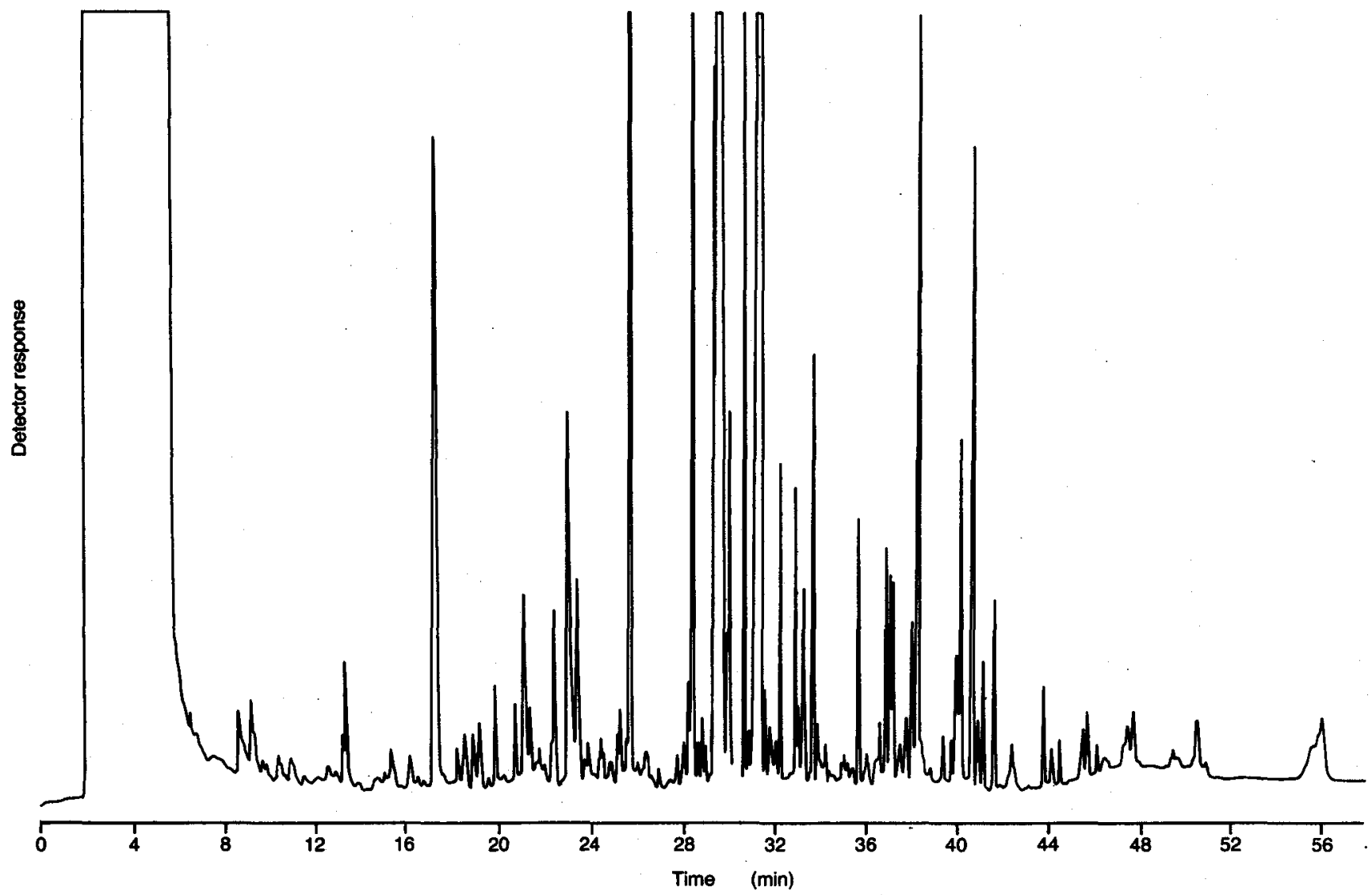

Figure 6.

- Chromatogram of the free volatlle fatty acids (underivatized) from the saponification of a sucrose ester fraction using a Pyrex glass SP-1000 wall-coated open-tubular (WCOT) capillary column. Conditions: $120-220^{\circ} \mathrm{C}$ at $6 \% / \mathrm{min} ; 30 \mathrm{~cm} / \mathrm{s} \mathrm{H}_{2}$ flow; split injection mode; FID; $30 \mathrm{~m}$ × $0.25 \mathrm{~mm}$ inside diameter.

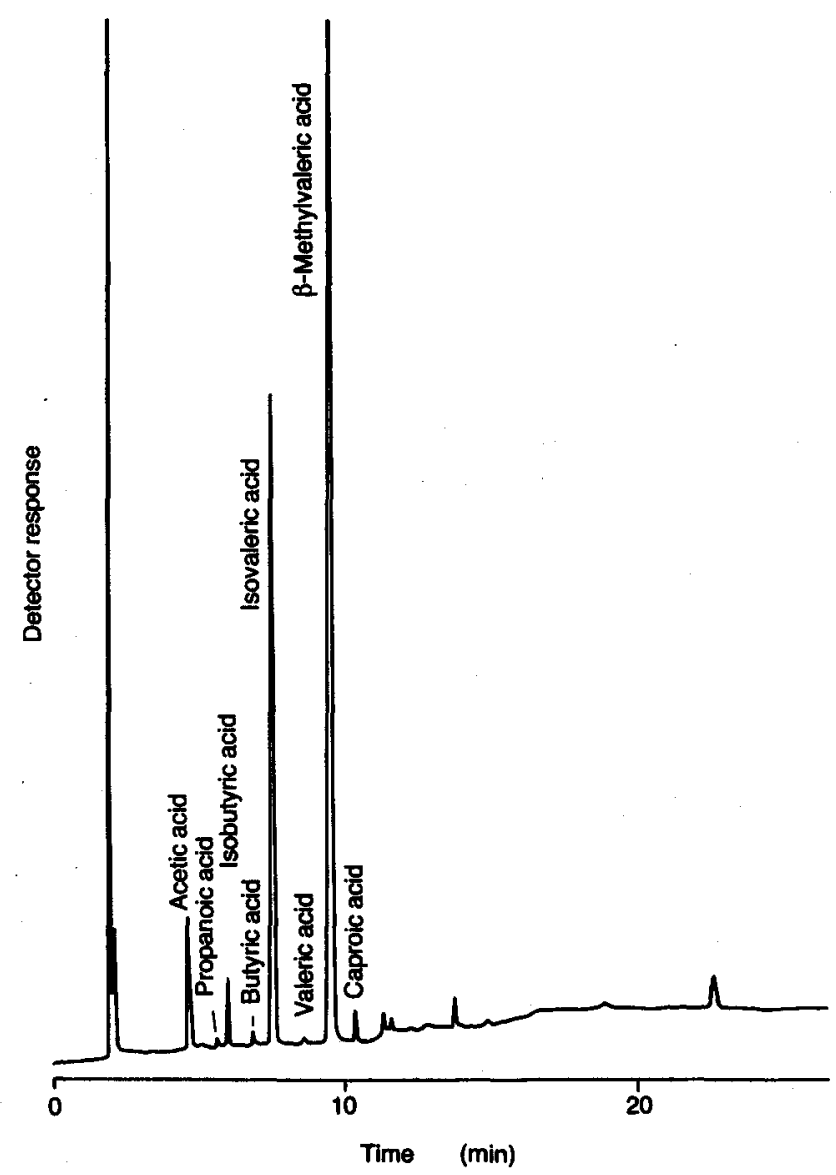


Figure 7.

Chromatogram of the tobacco leaf surface wash acids (fatty acid methyl esters (FAME)) and the whole green leef acids (fatty acld methyl esters (FAME)) from NC-2326 tobacco on a Pyrex glass Superox-4 wall-coated open-tubular (WCOT) caplliary column. Conditions: $150-2500^{\circ} \mathrm{C}$ at $44^{\circ} / \mathrm{min}$; $25 \mathrm{~cm} / \mathrm{s}$ He flow; split injection mode; FID; $25 \mathrm{~m} \times 0.25 \mathrm{~mm}$ inside diameter.

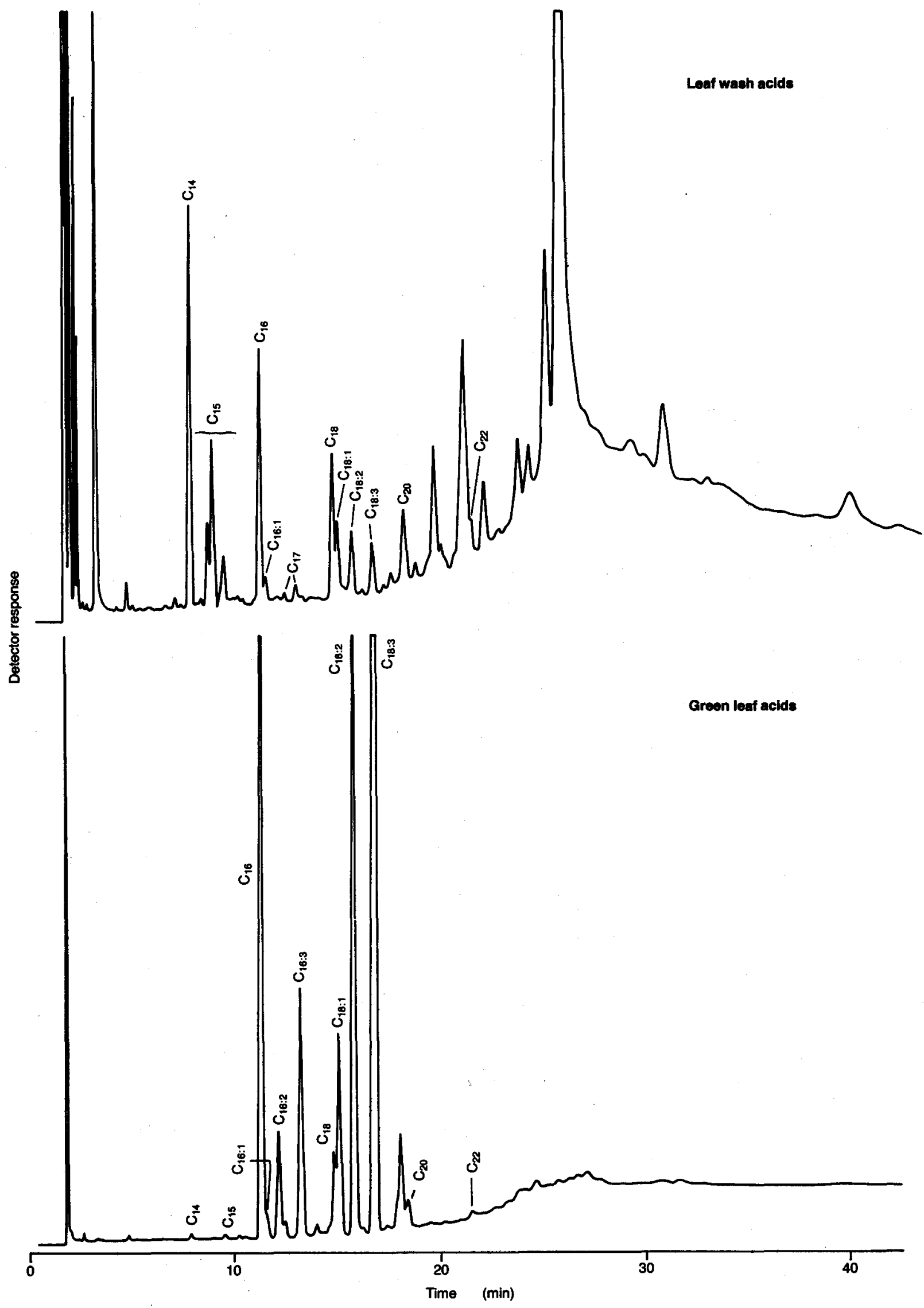




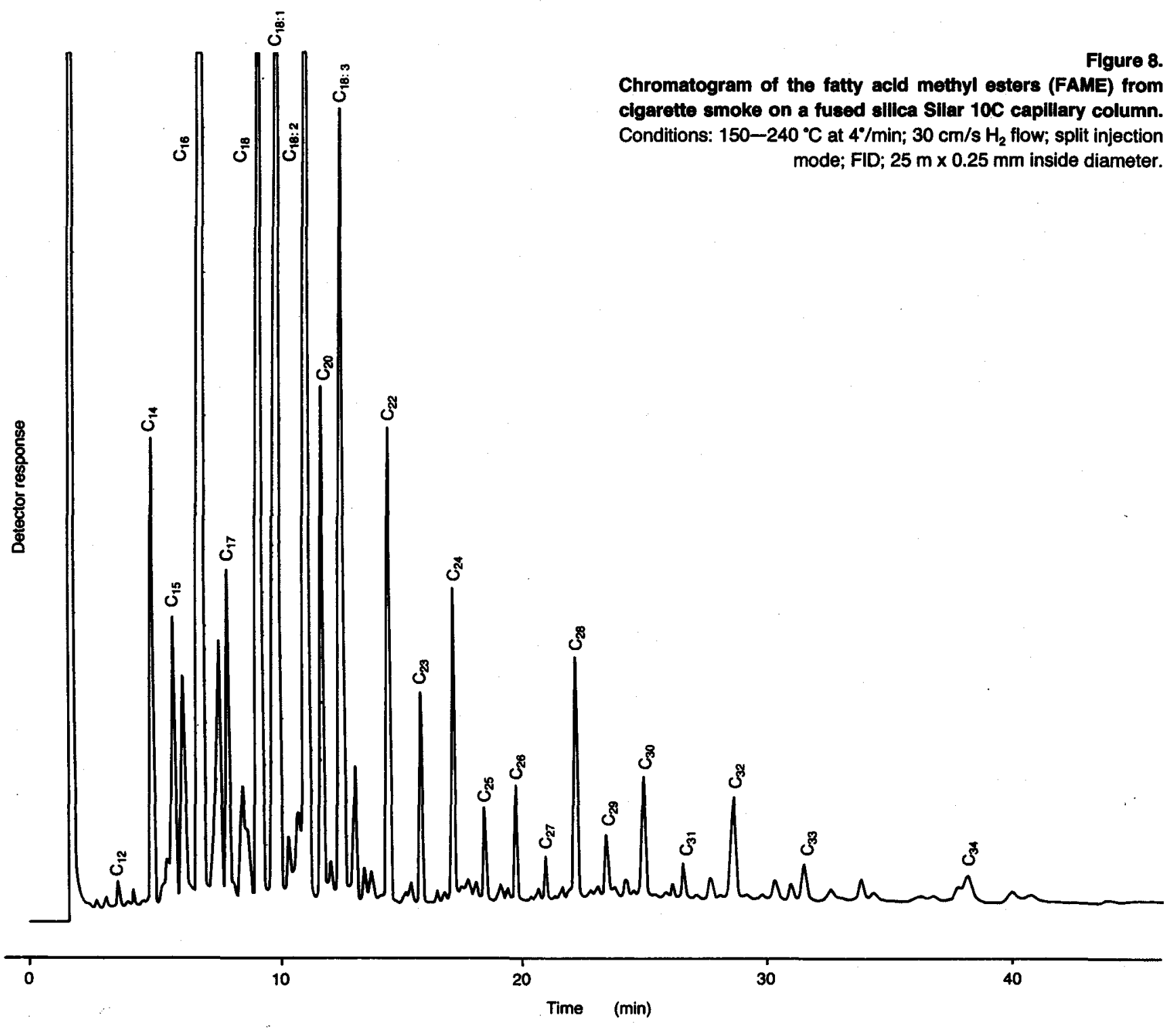

tained from leaf surface washes and subjected to saponification with $2 \mathrm{~N} \mathrm{KOH}$ in a $80 \%$ methanol/water mixture to release the volatile acids. The acids after adjusting the $\mathrm{pH}$ to 2 with concd. $\mathrm{HCl}$ were chromatographed on an SP-1000 capillary column (Figure 6). Large amounts of isovaleric and $\beta$-methylvaleric acid, a major contributor to the Turkish tobacco smoke aroma, were found.

Tobacco leaves also contain long-chain fatty acids. Substantial amounts of these fatty acids are transferred to tobacco smoke during the smoking process (42). Fatty acids are normally chromatographed as their methyl esters (FAME) (11) and can be separated on Superox-4 capillary columns (15). Two GC profiles of FAME from green tobacco leaf and from a tobacco leaf surface wash are given in Figure 7. Note the differences in distribution of the fatty acids in these samples. In the total green leaf acids isolate, the normal plant fatty acids predominate, while in the leaf surface wash acids isolate, another series of acids are present, which are de- rived from cuticular wax esters (12) and are discussed below.

The very polar liquid phase, Silar $10 \mathrm{C}$, is excellent for separating fatty acid methyl esters (FAME). However, until recently, no commercial fused silica (FS) Silar 10C capillary columns were available. We modified our Superox-4 pretreatment and deactivation procedure to successfully prepare FS Silar $10 \mathrm{C}$ capillary columns in the laboratory (11). The fatty acids from tobacco smoke were isolated in a subfraction (F-61) $(43,23)$ as previously described. Using gel permeation chromatography, Snook et al. isolated a fatty acids fraction from Fraction F-61. The acids were converted to their FAME (11) and separated on a FS Silar 10C capillary column (Figure 8). Studies have shown that about $14 \%$ of the major plant fatty acids $\left(\mathrm{C}_{14}-\mathrm{C}_{18}\right)$ transfer to the smoke of a non-filter cigarette, with palmitic acid $\left(\mathrm{C}_{16}\right)$ having the highest transfer rate $(17.6 \%)$ and the $C_{18}$ unsaturated isomers (oleic, linoleic, and linolenic) having the lowest $(12.2 \%)$ rate of transfer (42). 


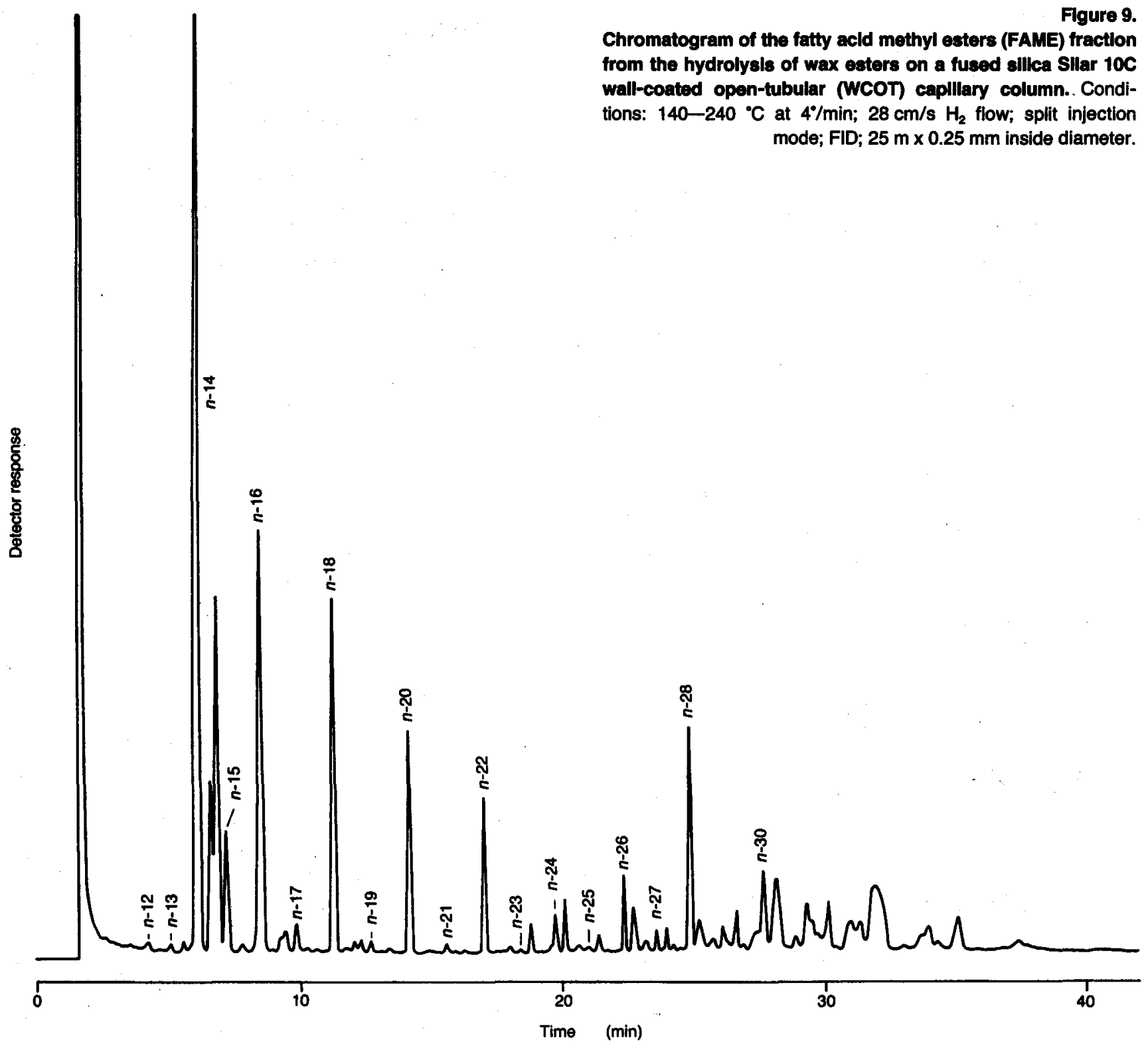

Recently, Severson et al. reported on the discovery of a series of high molecular weight wax esters found on the surface of green tobacco $(12,44)$. These esters were composed of $\mathrm{C}_{12}-\mathrm{C}_{30}$ acids bound to $\mathrm{C}_{18}-\mathrm{C}_{30}$ alcohols. Saponification of a pure isolate of wax esters with $2 \mathrm{~N} \mathrm{KOH}$ in $85 \%$ ethanol/water yielded the acid salts and alcohols. The ethanol/water mixture was extracted with hexane to remove the alcohols followed by adjustment of the $\mathrm{pH}$ to 2 with concd. $\mathrm{HCl}$ to yield the free acids. The acids were extracted into chloroform, blown to dryness with dry $\mathrm{N}_{2}$, and converted to their methyl esters (FAME) as previously described (11). The separation on an FS Silar $10 \mathrm{C}$ column of the derivatized FAME from the wax esters is shown in Figure 9. This GC-2 analysis assisted in characterizing the wax esters by identifying and quantitating the acid portions of these molecules.

\section{CONCLUSIONS}

Glass capillary gas chromatography is a powerful analytical tool and is well suited to analyses of biologically significant acids and phenolics of tobacco and tobacco smoke. Successful application of GC-2 methodology requires careful consideration of each facet of the chromatographic process. Over the last few years, we have demonstrated that the development of methodology for the laboratory preparation of glass capillary columns is well worth the effort. Our research goals of developing tobacco with good flavor and aroma, but with reduced health hazards, will require further innovative applications of state-of-the-art analytical methodology. Capillary gas chromatography will most certainly be a major factor in this research effort. 


\section{REFERENCES}

1. Severson, R. F., K. L. McDuffie, R. F. Arrendale and $O$. T. Chortyk: A modified method for the rapid analysis of long-chain alkanes and neophytadiene from tobacco; Beitr. Tabakforsch. Int. 11 (1981) 27-32.

2. Severson, R. F., K. L. McDuffie, R. F. Arrendale, G. R. Gwynn, J. F. Chaplin and A. W. Johnson: Rapid method for the analysis of tobacco nicotine alkaloids; J. Chromatogr. 211 (1981) 111-121.

3. Chamberlain, W. J., and R. F. Arrendale: Rapid method for the analysis of volatile $N$-nitrosamines in cigarette smoke by glass capillary chromatography; J. Chromatogr. 234 (1982) 478-481.

4. Arrendale, R. F., R. F. Severson, O. T. Chortyk and M. E. Snook: Analyses of mono- and dihydroxybenzenes in tobacco smoke and pyrolyzates by glass capillary gas chromatography; J. Chromatogr. Sci. 20 (1982) 136-143.

5. Chamberlain, W. J., and R. F. Arrendale: An alternate method for the analysis of $N$-nitrosonornicotine in tobacco; J. Agric. Food Chem. 31 (4) (1983) 909-911.

6. Severson, R. F., G. R. Gwynn, J. F. Chaplin and J. D. Miles: Leaf trichome exudate associated with insect resistance in Nicotiana tabacum L.; Tob. Sci. 27 (1983) 82-83.

7. Schlotzhauer, W. S., and O. T. Chortyk: Effects of varied smoking machine parameters on deliveries of total particulate matter and selected smoke constituents from an ultra low-tar cigarette; J. Anal. Toxicol. 7 (1983) 92-95.

8. Snook, M. E., and O. T. Chortyk: Capillary gas chromatography of carbolines, Application to cigarette smoke; J. Chromatogr. 245 (1982) 331-338.

9. Johnson, A. W., and R. F. Severson: Physical and chemical leaf surface characteristics of aphid resistant and susceptible tobacco; Tob. Sci. 26 (1982) 98-102.

10. Schlotzhauer, W. S., R. M. Martin, M. E. Snook and R. E. Williamson: Pyrolytic studies on the contribution of tobacco leaf constituents to the formation of smoke catechols; J. Agric. Food Chem. 30 (1982) 373-374.

11. Arrendale, R. F, G. W. Chapman and O. T. Chortyk: Gas chromatographic analysis of fatty acids on laboratory prepared fused silica Silar $10 \mathrm{C}$ capillary columns; J. Agric. Food Chem. 31 (1983) 13341338.

12. Severson, R. F., R. F. Arrendale, O. T. Chortyk, A. W. Johnson, D. M. Jackson, G. R. Gwynn, J. F. Chaplin and M. G. Stephenson: Quantitation of the major cuticular components from green leaf of different tobacco types; J. Agric. Food Chem., in press.

13. Snook, M. E., O. T. Chortyk and R. F. Arrendale: Isolation and identification of $N^{\prime}$-acylalkaloids of cigarette smoke; Beitr. Tabakforsch. Int., Vol. 12 (1984), in press.
14. Arrendale, R. F., L. B. Smith and L. B. Rogers: Comparison of dynamically coated SE-54, SP-2250 and Carbowax 20M wall-coated open tubular (WCOT) glass capillary columns, prepared after surface pretreatment with Superox ${ }^{\mathrm{TM}_{-} 4}$ or with $\mathrm{BaCO}_{3}$; J. HRC and CC 3 (1980) 115-123.

15. Arrendale, R. F., R. F. Severson and O. T. Chortyk: Preparation of wall-coated open tubular glass (Pyrex) capillary columns with polar stationary phases, using Superox ${ }^{\mathrm{MM}_{-4}}$ as a surface pretreating and deactivating agent; J. Chromatogr. 208 (1981) 209-216.

16. Arrendale, R. F., R. F. Severson and O. T. Chortyk: Preparation of fused silica polar stationary phase WCOT columns; J. Chromatogr. 254 (1983) 63-68.

17. Arrendale, R. F., R. F. Severson and O. T. Chortyk: Simple alternative method for preparing high quality fused silica SE-54 WCOT capillary columns; J. HRC and CC 6 (1983) 436-440.

18. Van Duuren, B. L., C. Katz and B. M. Goldschmidt: Cocarcinogenic agents in tobacco carcinogenesis; J. Natl. Cancer Inst. 51 (1973) 703705.

19. Van Duuren, B. L., and B. M. Goldschmidt: Cocarcinogenic and tumor-promoting agents in tobacco carcinogenesis; J. Natl. Cancer Inst. 56 (1976) 1237-1242.

20. Roe, F. J. C., M. H. Salaman and J. Cohen: Incomplete carcinogens in cigarette smoke condensate, Tumor-promotion by a phenolic fraction; Br. J. Cancer 3 (1959) 623-633.

21. Wynder, E. L., and D. Hoffmann: A study of tobacco carcinogenesis, VIII. The role of acidic fractions as promoters; Cancer 14 (1961) 1306-1315.

22. Bock, F. G., A. P. Swain and R. I. Stedman; Composition studies on tobacco, XLIV. Tumor-promoting activity of subfractions of the weak acid fraction of cigarette smoke condensate; J. Natl. Cancer Inst. 47 (1971) 429-436.

23. Walters, D. B., W. J. Chamberlain, F. J. Akin, M. E. Snook and $O$. T. Chortyk: Fractionation of cigarette smoke condensate for chemical and biological testing; Anal. Chim. Acta 99 (1978) 143-150.

24. Hecht, S. S., R. L. Thorne, R. R. Maronpot and D. Hoffmann: A study of tobacco carcinogenesis, XIII. Tumor promoting subfractions of the weakly acidic fraction; J. Natl. Cancer Inst. 55 (1975) 1329-1336.

25. Kallianos, A. G.: Phenolics and acids in leaf and their relationship to smoking quality and aroma; Recent Adv. Tob. Sci, 2 (1976) 61-79.

26. Snook, M. E., and O. T. Chortyk: An improved extraction-HPLC method for polyphenols; Tob. Sci. 26 (1982) 25-29.

27. Lee, M. L., and B. W. Wright: Preparation of glass capillary columns for gas chromatography; $\mathrm{J}$. Chromatogr. 184 (1980) 235-312.

28. Dandeneau, R. F., and E. H. Zerenner: An investigation of glasses for capillary chromatography; J. HRC and CC 2 (1979) 351-356. 
29. Lipsky, S. R., W. J. McMurray and M. Hernandez: Fused silica glass capillary columns for gas chromatographic analyses; J. Chromatogr. Sci. 18 (1980) 1-9.

30. Pretorious, V., and D. H. Desty: The activity of siliceous capillary columns for gas-liquid chromatography; J. HRC and CC 4 (1981) 38-39.

31. Jennings, W. G.: Comparisons of fused silica and other glass columns in gas chromatography; Alfred Hüthig Verlag $\mathrm{GmbH}$, Heidelberg, 1981.

32. Grob, K., Jr., and K. Grob: Are we using the full range of film thickness in capillary GLC; Chromatographia 10 (1977) 250-255.

33. Arrendale, R. F., and O. T. Chortyk: Capillary gas chromatography using a laboratory-constructed cold on-column inlet system; Proceedings of the 35th Southeastern Regional American Chemical Society Meeting, Charlotte, N. C., November 9-11, 1983.

34. Grob, K, Jr.: Peak broadening or splitting caused by solvent flooding after splitless or cold on-column injection in capillary gas chromatography; J. Chromatogr. 213 (1981) 3-14.

35. Grob, K., Jr., and R. Müller: Some technical aspects of the preparation of a "retention gap" in capillary gas chromatography; J. Chromatogr. 244 (1982) 185-196.

36. Severson, R. F., R. F. Arrendale and O. T. Chortyk: Simple conversion of two standard gas chromatographs to all-glass capillary systems; J. HRC and CC 3 (1980) 3-7.

37. Snook, M. E., P. J. Fortson and O. T. Chortyk: Application of gel chromatography to characterize more completely the phenols of cigarette smoke; Tob. Sci. 24 (1980) 30-36.

38. Snook, M. E., and O. T. Chortyk: Isolation and identification of phenolic acids in smoke by gel adsorption and fused silica capillary gas chromatography; Abstracts of papers, 36th 'Tobacco Chemists' Research Conference, Raleigh, N. C., October 25$27,1982$.

39. Schumacher, J. N.: The isolation of 6-O-acetyl2,3,4-tri-O- $[(+)$-3-methylvaleryl $]-\beta$-D-glucopyranose from tobacco; Carbohydr. Res. 13 (1970) $1-8$.
40. Rivers, J. M.: Low molecular weight fatty acid sugar esters in Turkish tobacco, Separation by reversephase high performance liquid chromatography and spectral characterization; Abstracts of papers; 35th Tobacco Chemists' Research Conference, WinstonSalem, N. C., October 7-9, 1981.

41. Severson, R. F., R. F. Arrendale, O. T. Chortyk and A. W. Johnson: The isolation of possible cigarette smoke flavor compounds from green tobacco leaf; Proceedings of the 32nd Southeastern Regional American Chemical Society Meeting, Lexington, Ky., November 4-6, 1981.

42. Severson, R. F, R. F. Arrendale, O. T. Chortyk and M. E. Snook: A method for determining the transfer of lipids from tobacco to smoke; Tob. Sci. 22 (1978) 130-133.

43. Chamberlain, W. J., D. B. Walters, M. E. Snook, O. T. Chortyk and F. J. Akin: Fractionation of cigarette smoke condensate for biological testing, Concentration of polynuclear aromatic hydrocarbon and weak-acid fractions; Beitr. Tabakforsch. 8 (1975) 132-135.

44. Severson, R. F., R. F. Arrendale, J. F. Chaplin, G. R. Gwynn and A. W. Johnson: The cuticular chemistry of green tobacco leaf; Abstracts of papers, 35th Tobacco Chemists' Research Conference, Winston-Salem, N. C., October 7-9, 1981.

\section{Acknowledgements}

The authors wish to thank Robert M. Martin, Patricia $F$. Mason, Linda B. Smith, and Katheryn $L$. McDuffie for technical assistance in the completion of this work.

Authors'address:

U.S. Department of Agriculture, Agricultural Research Service, Southern Region, Ricbard B. Russell Agricultural Research Center, P.O. Box 5677, Athens, Georgia, 30613, U.S.A. 